desselben war 2,0900 Grm., also nur um 0,0015 Grm. geringer, als es ursprünglich gewesen. Als von diesem Oxyde nun 2,089 Grm. in einem Flintenlaufe unter getrocknetem Wassersloffgase einer mässigen Rothglihhitze ausgeselzt wurden, so wurden $1,458 \mathrm{Grm}$. graues Eisenpulver erhalten, oder 69,7942 Proc. des gegluheten Oxyds. Nach dem Berzelius'schen Atomgewichte des Eisens hätten aber nur 69,338 Proc. erhalten werden müssen. Oben ist aber zu zeigen versucht worden, dass der Gewichtsverlust des Eisenoxyds beim Rothgluhen in Wasserstoffgas nicht 30,66 Proc., sondern nach Stromeyer's fruherer Angabe nur 30,15 Proc., und meiner Meinung nach meistens selbst nur 30,028 Proc. beträgt. Hier hatte das Eisenoxyd bei sciner völligen Reduction durch trocknes Wasserstoffgas in der Gliihhitze 30,2058 Proc. an Gewicht verloren.

Obgleich eine Erneuerung dieser Versuche zur Bestätigung der Resultate wünschenswerth, ja nothwendig erscheint, so dürften dieselben doch auch in ihrer gegenwärtigen Begrenzung der Beachtung nicht unwerth erscheinen.

\title{
Einige Bemerkungen über die Bereitung des Uranoxyds und der Titansäure zn technischen Zwecken ;
}

\author{
von \\ O. Köhnke,
}

d. Z. in Garding.

Bekanntlich wird das Uranoxyd, sowie die Titansäure zu Feuermalerei, und das Uranoxyd ausserdem zur feinen Oelmalerei angewandt. Weniger bekannt möchte es sein, dass beide Präparate auch zur Bereitung der künstlichen Zähne gebraucht werden, um nämlich die verschiedenen Farbentöne in dieser Emaillemasse hervorzurufen. $\mathrm{Zu}$ sämmtlichen Zwecken habe ich beido Präparate in ziemlicher Menge dargestellt, und erlaube mir daher einige Bemerkungen darüber, da dieselben noch nicht zu den 
gewöhnlichen Handelsartikeln gehören und deshalb mehrfach in Apotheken verlangt werden möchten *).

Das Uranoxyd, um es chemisch rein darzustellen und als salpetersaures Salz zum Reagens zu verwenden, wurde nach verschiedenen Angaben bereitet, und zwar nach Duflos, Herschel, Ebelmen und Peligot. Peligot's Verfahren muss ich den Vorzug cinräumen, da die Darstellungsweise höchst einfach ist und ein ausgezeichnetes, chemisch reines Präparat liefert. Um das Uranoxyd nun zu den gedachten Zwecken zu verwenden, wurde eine Abänderung des Peligot'schen Verfahrens befolgt, da es sich durch mehrfache Versuche erwies, dass ein eisenhaltiges Oxyd, nach folgender Angabe bereitet, dieselben Dienste leistete.

Bemerken muss ich jedoch zuvor, dass zur Bereitung des Uranoxyds Pechblende, angeblich aus dem sächsischen Erzgebirge, zur Titansäure 'Titaneisen, angeblich von Egersund, sowie Rutil in Fragmenten, von Käringsbricka, angewandt wurden.

Feingepulverte und geschlemmte Pechblende wird mit verduinnter Salzsäure übergossen und unter bisweiligem Umrühren einige Zeit hingestellt, um die Erden und das Manganoxydul auszaziehen, sodann ausgewaschen und getrocknet, mit dem 2fachen Gewichte roher concentrirter Salpetersäure gekocht und zur Trockne gebracht.

Nachdem die rückständige Masse mit Wasser ausgezogen worden, wird in die filtrirte Auflösung Schwefelwasserstoff geleitet bis zur völligen Abscheidung der fremdartigen Metalle, Kupfer, Blei, Arsen u. s. w. Ilie filtrirte Flüssigkeit wird nochmals zur Trockne gebracht, wobei noch ein ansehnlicher Buickstand von Eisenoxyd bei abermaliger Lösung bleibt. Diese filtrirte salpetersaure Uranoxydfluissigkeit wird nun mit Aetzammoniak versetzt.

*) Eine Probe Uranoxyd, die durch den Handel bezogen und zur Feuermalerci als völlig unbrauchbar erkannt wurde, hatte ich Gelegenheit einer Untersuchung zu unterwerfen. Der Analyse zufolge bestand dieses küufliche Uranoxyd aus einem innigen Gemenge von unreinem Uranoxydkali mit chromsaurem Bleioxyd. 
Der gelbe Nicderschlag von Uranoxyd-Ammoniak wird gesammelt, ausgesiisst, getrocknet und sofort erhitzt, worauf ein lebhaft orangefarbenes Uranoxyd erhalten wird.

Obgleich ein solches Uranoxyd auch Ammoniak und Eisen, sowie Spuren von Zink, Mangan und Kobalt enthält, so zeigt das Aeussere desselben keinen wesentlichen Unterschied von dem chemisch reinen Oxyde.

Die Ausbeute betrug aus 100 Theilen dieser Pechblende durchschnittlich $500-60$ Theile Uranoxyd.

Nach Herschel's Angabe bereitete ich das Uranoxyd früher, nämlich durch Auflösen des Minerals in. Salpetersäure, Füllen mit Kaliumeisencyanür, sodann Auflösen des braunrothen Niederschlags in schwacher kohlensaurer Kalilauge und Fällen dieser Lösung vermittelst Aetzkalis. Das auf diese Weise erhaltene Uranoxydkali wird wiederum in Salzsäure aufgelöst und nun mit Aetzammoniak präcipitirt, worauf es ein recht reines, jedoch zu gedachten Zwecken verhältnissmässig theures Praparat wird. Ifierbei crhielt ich indessen nach der Auflösung des dureh Kaliumeisencyanür bewirkten Niederschlags einen Rückstand, der grösstenthcils aus Eisenoxyd bestand. Dieses war von carmoisinrother Farbe und erzeugte mit Bleiwciss und austrocknendem Oel präparirt, eine lebhafte Fleischfarbe, und wurde deshalb von einem Decorationsmaler als einc besonders schöne Farbe erkannt und angewandt.

Die Titansäure aus dem Titaneisen bereitet, wurde ebenfalls als eisenhaltige Titansäure dargestellt und entsprach völlig ihrem Zweck.

Das Mineral wird $\mathrm{zu}$ diesem Behufe, wie es von R o se angegeben, feingepulvert, geschlämmt, getrocknet, mit dem halben Gewichte Schwefel innig gemengt und geglüht. Die darauf erkaltete gepulverte und geschlämmte Masse wird mit concentrirter Salzsïure übergossen, und nachdem man das Eisen ausgezogen, gewaschen, getrocknet und schwach geglüht. Bei dem Glühen gelingt die Verbindung des Schwefels mit dem Eisen nicht immer gleich gut, indem ein gewisser Grad der Hitze getroflen werden soll, ähnlich wie bei der Darstellung des Schwe- 
feleisens. Man verfährt demnach, wie ich fand, besser, wenn man das innig gemengte Pulver in einen rothgliihenden Schmelztiegel portionenweise einträgt, und jedesmal wartet, wie bei ähnlicher Bereitung des Schwefeleisens, bis die innige Verbindung durch das bezeichnende Erglühen eintritt.

Nachdem Alles eingetragen, wird der Tiegel bedeckt, noch eine kurze Zeit im Glühen erhalten, sodann die erkaltete Masse weiter behandelt.

Die so dargestellte Titansäuro ist verunreinigt mit Eisen und Spuren von Mangan und Zinn, und stellt ein gelblichweisses Pulver dar. 100 Theile Titaneisen lieferten gewöhnlich 85-90 Theile Titansäure.

Die Titansäure aus dem Rutil wird bereitet, indem das geschlämmte Mineral mit 4 Theilen von einem Gemenge aus gleichen Theilen zerfallenem kohlensaurem Natron und trocknem kohlensaurem Kali innig gemengt, geschmolzen, die erkaltete Masse vermittelst Wassers von dem überschüssigen Alkali befreit, der Rückstand, grösstentheils titansaures Kali und.Natron, in concentrirter Salzsäure aufgelöst, mit Wasser verdiunnt, filtrirt und nun mit Aetzammoniak präcipitirt wird.

Der Niederschlag getrocknet und geglüht, giebt ebenfalls eine gelblichweisse Titansäure, und zwar in derselben Menge, wie aus dem Titaneisen.

\title{
Ueber die bei der Anwendung des Marsh'schen Apparates gemachte Bemerkung, dass auch Wismuth, ferner Schwefelarsen und Schwefel- antimon im Wasserstoff löslich und durch Verbrennen desselben wieder abgeschieden werden können;
}

\author{
ron \\ D. Friedrich Meurer, \\ Apotheker zu Dresden.
}

Die vielen Versuche, welche ich mit der Methode von Marsh angestellt habe, theils um das Arsen in anorgani-

Arch. d. Pharm. LXXXVI. Bds. 1. Hft. 